\title{
De las buenas familias del valle de Toluca: los Villanueva. Un ejemplo de la vinculación de la propiedad a través de la institución del mayorazgo, siglos $\mathrm{XVII}-\mathrm{XIX}$
}

From the Good Families in Toluca Valley: A Study of Property Connections through Entailed Estate (mayorazgo), 17th - 19th Century

Florencio Barrera Gutiérrez

Facultad de Filosofía y Letras

Universidad Nacional Autónoma de México

florenciobarrera4@gmail.com

Recibido: 30 de mayo de 2017 • Aprobado: 7 de junio de 2017

\section{Resumen}

En este artículo se examina el proceso del vínculo de una familia y sus propiedades a través de la institución del mayorazgo, desde el siglo XVII hasta la primera mitad del siglo XIX. Se percibirá entonces la trayectoria de una propiedad familiar, de miembros de la naciente elite novohispana, que a lo largo de varias generaciones logran edificar, conservar y aumentar un conjunto de bienes, principalmente agrícolas, en los pueblos de Otzolotepec, Jilotzingo, Mimiapan y Xonacatlán, ubicados en el valle de Toluca. El mayorazgo de Villanueva, cuyo apellido familiar dio nombre, no fue excesivamente productivo, sino que correspondía a una familia de la nobleza que, con esfuerzo y dedicada labor, y aun con problemas a su alrededor, perpetuó en muchos sentidos. Así estuvo presente hasta la tercera década del siglo XIX. Durante poco más de doscientos treinta años, se sucedieron, al frente de los destinos del mayorazgo once personajes.

Palabras clave: valle de Toluca, familia, mayorazgo, tierras, Villanueva

\section{Abstract}

This article examines the connections between a family and its properties under entailed estate (mayorazgo) from the seventeenth century into the first half of the nineteenth century. The article then investigates the trajectory of familial property of the nascent New Hispanic elite's members who over various generations managed to build, preserve and increase a collection of goods, primarily agricultural, in the villages of Otzolotepec, Jilotzingo, Mimiapan and Xonacatlán. The mayorazgo de Villanueva, whose name came from its family surname, was not excessively productive but corresponded to a family of nobility that with effort and dedicated labor, even with surrounding problems, perpetuated itself in many ways. Thus, it was present until the third decade of the nineteenth century. For little more than 230 years, eleven people followed one another to the front of destiny through their entailed estate.

Keywords: Toluca Valley, family, mayorazgo, lands, Villanueva 


\section{Introducción}

Muchos fueron los españoles que participaron en la conquista, la pacificación y el poblamiento de diferentes lugares de la Nueva España. Sin embargo, poco sabemos sobre la vida de cada uno de aquellos conquistadores que abandonaron su patria, pero sin duda, cada uno trataba de sentar las bases de su futuro a la vez de afianzar sus logros para figurar en la vida social y política del nuevo orden, adquirir fortuna y privilegios para asegurar su futuro en el nuevo territorio conquistado. En el valle de Toluca las familias Villanueva, Suárez de Peralta, Cervantes, Gutiérrez Altamirano y Sámano, resultan interesantes debido a que llegaron a tener gran impacto y presencia importante en los pueblos de sus encomiendas, por consolidar intereses agrarios y formar fortunas importantes.

Geográficamente, tomando como centro Toluca, que quedó en manos de Hernán Cortés como parte de su concesión real, los Villanueva estuvieron presentes en los pueblos de Otzolotepec, Jilotzingo, Mimiapan y Xonacatlán. El linaje Suárez de Peralta en Huitzizilapan, Tlalmimilolpan y Xochicuautla. La familia Cervantes en Atlapulco y Jalatlaco, Gutiérrez Altamirano en Metepec, Calimaya y Tepemajalco, y la familia Sámano en Zinacantepec. La presencia estratégica de estas familias alrededor de Toluca los colocó en una situación de privilegio. Además, un denominador común en todas ellas no solo se reflejó en relaciones de amistad, sociales o de negocios, sino también en lazos familiares a través de las uniones matrimoniales, que fueron de gran importancia ante cualquier eventualidad.

El matrimonio de Alonso de Villanueva Tordesillas, conquistadorencomendero, con Ana de Cervantes, hija de Leonel de Cervantes, en 1527, marca el inicio de la historia de la distinguida familia Villanueva, no solo en el valle de Toluca, sino también en la Nueva España. La pareja manifestó un constante interés por ganar honra y riqueza, así como el deseo de alcanzar y mantener una posición en la sociedad colonial durante la primera mitad del siglo xvi. Además, el comportamiento, la relación con funcionarios y el valor de Villanueva Tordesillas en diferentes hechos de armas (de Tenochtitlán, la expedición a 
Pánuco, en la provincia de Yopelcingo y en Colima, así como en la guerra del Mixtón) le valieron ocupar puestos de alguna importancia en el cabildo de la Ciudad de México, la encomienda de cuatro pueblos (Jilotzingo, Mimiapan y Otzolotepec y su sujeto Xonacatlán, en el valle de Toluca, y Huauchinango, en la sierra norte de Puebla), un escudo de armas y la concesión de mercedes de tierras.

Si bien el caso de los Villanueva no resulta ser un hecho aislado, será el tema que nos ocupe para examinar el proceso histórico que relacionó por siglos a una familia y sus propiedades, así como la estrategia seguida por uno de los descendientes de Alonso de Villanueva Tordesillas y Ana de Cervantes, particularmente el segundogénito: Alonso de Villanueva Cervantes, para perseguir el sueño señorial a principios del siglo xvir. Su importancia se debe al hecho de que planeó la forma de asegurar y conservar unida casi la totalidad del patrimonio heredado y adquirido durante el siglo xvi, a través de la institución del mayorazgo.

\section{El mayorazgo como forma de conservar las fortunas familiares}

En la segunda mitad del siglo xvi los linajes notables del valle de Toluca estaban conformados por un grupo privilegiado, provenientes de las familias que llegaron al nuevo territorio recién conquistado, todos muy bien relacionados con el poder político, ocupando importantes puestos, unidos mediante enlaces matrimoniales convenientes, vinculados con las actividades económicas más lucrativas y con fortunas considerables. La adquisición de bienes y fortuna, sin duda, fue importante pero también su conservación.

La institución del mayorazgo tiene gran importancia y trascendencia debido a que representó durante la época Colonial, para algunos colonos españoles, un mecanismo para continuar con las aspiraciones señoriales a través de la vinculación de determinados bienes que se apartaban del orden de herencia para quedar en manos de un solo representante, generalmente el primogénito. Pero también para proporcionar a la rama principal de la familia un respaldo económico 
que le permitiera mantener un estatus socioeconómico y de prestigio por generaciones mediante el carácter de inalienable, indivisible e imprescindible de los bienes. O como señala José de la Peña, para mantener las "bases patrimoniales de la oligarquía novohispana".

Así se pretendía evitar que el reparto de los bienes adquiridos, que se concebía de manera regular al interior de la familia, desembocara en la dispersión. Es importante resaltar que la fundación de un mayorazgo fue un privilegio concedido solo a la nobleza. A través de un testamento o de una escritura pública - hecha generalmente por un matrimonio y siempre con licencia real-se disponía que una parte del patrimonio; el quinto y el tercio, se apartaba del orden de herencia para ser transmitido a manos de un solo representante de la familia. El titular no podía disponer libremente de dicho patrimonio al ser usufructuario y no propietario de los bienes.

En este contexto, Guillermo Margadants señala que el mayorazgo era como un usufructo en cadena, porque el titular de los bienes no tenía el ius abutendi o el derecho de disponer de estos bienes. Por lo tanto, el poseedor no podía vender, donar o grabar los bienes, o disponer de ellos mortis causa. ${ }^{2}$ Ante el impedimento de enajenar los bienes, se esperaba que cada nuevo beneficiario hiciera producir los bienes y los conservara íntegros, con la posibilidad de incrementarlos, pero nunca reducirlos para, a su vez, transferirlos a la siguiente generación, de acuerdo con las normas de sucesión establecidas por los fundadores.

Conservar el patrimonio fue una de las preocupaciones de los fundadores, de ahí que se obligara a los titulares a mantenerlos en buenas condiciones para que fueran productivos y se conservaran el tiempo que fuera posible. En una cláusula de la escritura de fundación del mayorazgo de Juan Gutiérrez Altamirano, de 1558, se establecía que los poseedores tenían la obligación de conservar todos los bienes vinculados. En caso de que el titular no conservara las propiedades debía pasar al siguiente, de acuerdo con la sucesión

${ }^{1}$ De la Peña, Oligarquía y propiedad en la Nueva España, p. 219.

2 Margadants, "El mayorazgo novohispano", pp. 231-232. 
establecida. ${ }^{3}$ Así se refleja también en la escritura de fundación del Mayorazgo de Francisco Hernández de la Higuera, de 1605, donde se instituía que cada titular estaba obligado a laborar, conservar y reparar los bienes con el fin de acrecentarlos y ser transferidos a una nueva generación. ${ }^{4}$

Esta nueva forma de mantener patrimonio y privilegios, así como asegurar el paso de fortunas a las generaciones subsecuentes, en Nueva España y en el Virreinato del Perú, tiene su origen en Castilla. Bartolomé Clavero refiere que el mayorazgo se constituye a partir de la segunda mitad del siglo xiv, como consecución de un proceso de conformación jurídica de la propiedad señorial, su desarrollo sistemático fue a lo largo del siglo xv. ${ }^{5}$ Se configuró como una institución basada en la vinculación perpetua de un patrimonio formado por propiedades que darían a la familia la eternización dinástica y la gloria del grupo nobiliario, y fue regulado bajo las leyes de Toro de 1505. Las leyes de Toro disponían, entre otras cosas, para la vinculación patrimonial de una licencia real y de un testamento o escritura pública. ${ }^{6}$

${ }^{3}$ Archivo General de la Nación (en adelante AGN), Vínculos y mayorazgos, vol. 4, exp. 1, ff. 151-174.

${ }^{4}$ Bermúdez, El mayorazgo de la Higuera, pp. 46-69.

${ }^{5}$ Clavero, Mayorazgo. Propiedad feudal, primera parte.

${ }^{6}$ Leyes de Toro, principalmente las leyes 40 a 46. La creación de un vínculo podía darse, por vía de testamento, o bien por vía contractual y siempre con licencia real. El valor total de los bienes se dividía en quince partes iguales: tres de estas partes, representaba el quinto; cuatro de las doce partes restantes formaban el tercio. La vinculación se formaba del quinto y el tercio, es decir, siete de las quince partes de la propiedad del fundador, muchas veces incluso fue superior al tercio y al quinto. Las ocho partes restantes eran los bienes libres, que podían venderse, hipotecarse o heredarse a quien quisiera. Algunos autores consideran como precedente del mayorazgo los fideicomisos testamentarios romanos, los cuales permitían la sucesión predeterminada hasta por cuatro generaciones; el sistema feudal español; las propiedades eclesiásticas, ya que no podían ser enajenadas, y la ley de las siete partidas, promulgada bajo el reinado de Alfonso el sabio. Esta legislación establecía la sucesión monárquica castellana y la indivisibilidad del reino. Fernández de Recas, Mayorazgos de la Nueva España, pp. XI-XII; Clavero, Mayorazgo. Propiedad feudal, pp. 21-207 y Margadants, "El mayorazgo novohispano", pp. 231-232. 
Bajo las disposiciones peninsulares se establecieron en la Nueva España los mayorazgos. La figura jurídica del mayorazgo ha sido motivo de estudio por su importancia para las elites novohispanas y por conservar el patrimonio acumulado durante el siglo XVI, XVII o xviII. El estudio de Guillermo Fernández de Recas, Mayorazgos de la Nueva España, constituye uno de los primeros trabajos que reúne una serie de documentos de los mayorazgos establecidos en el periodo Colonial -que se localizan en los acervos conservados en el Archivo General de la Nación-, lo que le imprime su valor de consulta obligada para quien desee profundizar en el estudio de alguno de los vínculos aludidos y fundados en diferentes partes de la Nueva España. Además, aunado a otros documentos que se encuentran en el Archivo General de la Nación, en el valioso acervo documental del Archivo General Agrario y en archivos particulares, varios estudiosos como Alejandro Villaseñor y Villaseñor, François Chevalier, José de la Peña, M. Doris Ladd, Gilberto Bermúdez, María Vargas-Lobsinger y Jesús Gómez Serrano, han identificado, estudiado y aportado valiosos datos sobre esta institución.

A través de la historiografía académica podemos dilucidar como diferentes familias del territorio novohispano recurrieron a la forma jurídica que representaba el mayorazgo para conservar sus bienes, ampliar sus fortunas y para crear nuevas; al mismo tiempo para apreciar sus fortunas personales y familiares. Así como su participación en la economía y sus relaciones de parentesco y con la sociedad. Además, como algunas familias trataron de continuar con la ambición de sus aspiraciones señoriales, que habían iniciado con la encomienda.

Gloria Artís Espriu, señala que durante el periodo Colonial se fundaron en Nueva España alrededor de noventa mayorazgos, de los cuales 33 se crearon en el siglo xvi, 31 en el siglo xvir y unos 26 en el siglo xviIr. Es de resaltar que los que corresponden a los siglos Xvi y xvII, fueron fundados por conquistadores españoles o descendientes de conquistadores, a partir de su condición de conquistadores y nobles, cuyo más claro ejemplo sería el de Hernán Cortés, en 1535, el del conquistador-encomendero Juan Gutiérrez Altamirano, en 1558, o el del criollo Alonso de Villanueva Cervantes, descendiente del 
conquistador-encomendero Alonso de Villanueva Tordesillas, en 1605. Mientras que los del siglo xviII, fueron establecidos por los nuevos colonos españoles o por la nueva aristocracia del dinero, que compraba títulos, de hábitos de órdenes militares y fundaba mayorazgos por prestigio.

Algunos mayorazgos fueron duraderos y estuvieron presentes hasta la Ley de desvinculaciones en el siglo xix e incluso más allá. No obstante, la sobrevivencia no garantizaba que el conjunto de bienes que conformaban el mayorazgo (fincas urbanas y rurales) se conservaran intactos con el paso del tiempo, como era el deseo de sus fundadores. Muchas veces, ya fuera por coyunturas de crisis económica o malos manejos y la acumulación de deudas, las propiedades se veían menoscabadas al grado de que en ocasiones hubo necesidad de vender algunas de ellas, que habían tenido su mayor esplendor entre finales del siglo xvi y la primera mitad del siglo xviII.

A pesar de las transformaciones o cambios graduales que enfrentaron muchas familias nobles novohispanas durante el siglo XVI al XVIII lograron mantener los bienes para ser transferidos a una nueva generación, pero no su prosperidad. El fondo de la cuestión radicaba en el interés demostrado por los poseedores, por conservar y aumentar el patrimonio que se había forjado laboriosamente y que no estuviera sujeto a diversas vicisitudes. No podemos decir que el caso del "Mayorazgo de Villanueva" fue excesivamente productivo, sino que correspondía a una familia de la nobleza que con esfuerzo, dedicada labor y aun con problemas a su alrededor, perpetuó en muchos sentidos. Así, se mantuvo vigente hasta la tercera década del siglo xix. Durante poco más de doscientos treinta años se sucedieron al frente de los destinos de la herencia familiar 11 personajes. Este proceso de largo aliento nos permitió identificar y establecer sus etapas de crecimiento y estancamiento económico; así pudimos apreciar las fortalezas y debilidades de la institución del mayorazgo.

\section{La familia y las propiedades en el Mayorazgo de Villanueva}

El testamento de Alonso de Villanueva Cervantes, del 22 de enero de 1605, dio origen a la creación del mayorazgo que, casi al término 
de su vida, fundó todavía en unión de su esposa con la licencia que les concedió el rey Felipe in a principios de 1592. ${ }^{7}$ Este importante y extenso testamento consta de un preámbulo donde podemos observar la ferviente profesión de fe, a través de ceremonias litúrgicas, como las misas, las limosnas, mandas pías, herencias y otros actos de piedad. Este tipo de acciones tuvo gran significado para muchas familias debido a que representaba la religiosidad individual y familiar, pero también determinaban las condiciones económicas. Las disposiciones de Villanueva Cervantes corroboran su personalidad, caracterizada por una gran devoción en sus creencias religiosas.

Como también consta en el testamento, Alonso de Villanueva reunió un importante patrimonio de bienes muebles e inmuebles ubicados en la Ciudad de México y el valle de Toluca. Aun cuando no tenemos la certeza sobre el monto exacto de su fortuna, es indudable que amasó una riqueza espectacular en la segunda mitad del siglo xvi. De sus propiedades urbanas se tienen noticias de seis casas y cinco tiendas que compró por 10500 pesos a su suegro Juan Gutiérrez Altamirano. Alonso de Villanueva, junto con su esposa, fundó un mayorazgo que quedó conformado por una casa principal que poseían en la calle de los Donceles y cinco casas y 13 tiendas situadas en la "esquina que mira a las casas reales y a las dos plazas principales y reales" en la Ciudad de México. Así como de un sitio de estancia de ganado menor y mayor, 2535.88 hectáreas, "con sus casas, corrales, tierras y labores de pan llevar" en "términos" del pueblo de Otzolotepec, de un sitio de estancia de ganado mayor, 1755.61 hectáreas, "que incluía casas, tierras de labor y esclavos", y otro sitio de estancia de ganado menor, 780.27 hectáreas, en "términos" del pueblo de Mimiapan, en el valle de Toluca. ${ }^{8}$

La extensión de tierra vinculada no queda del todo clara. Aquí proponemos que la superficie territorial sujeta al mayorazgo fue más de 5071.76 hectáreas, es decir, se conformó con toda la tierra

\footnotetext{
${ }^{7}$ AGN, Vínculos y mayorazgos, vol., 193, exp. 9, ff. 6-13 y Archivo General Agrario (en adelante AGA), Otzolotepec, Villa Cuauhtémoc, México, exp. 23/2250, leg. 1, ff. 61-64. ${ }^{8}$ AGN, Vínculos y mayorazgos, vol. 194, exp. 1, ff. 1-22v y AGA, Otzolotepec, Villa Cuauhtémoc, México, exp. 23/2250, leg. 1, ff. 61-64.
} 
adquirida durante el siglo xvi por Alonso de Villanueva Tordesillas y Agustín y Alonso de Villanueva Cervantes, que fue de aproximadamente 9876.72 hectáreas. Esta propuesta se basa en el hecho de que Alonso de Villanueva Cervantes heredó algunas tierras de su padre y compró lo adquirido y heredado por Agustín de Villanueva Cervantes, además no se han localizado propiedades en manos de otros familiares de los Villanueva a finales del siglo xvi y principios del siglo xvir. De las 9876.72 hectáreas, 4681.62 hectáreas fueron adquiridas por Alonso de Villanueva Tordesillas a través de mercedes de tierras. Otra parte, 1058.4 hectáreas se obtuvieron por Agustín de Villanueva Cervantes vía mercedes tierras y cesión por parte de las autoridades de los pueblos de Otzolotepec, Jilotzingo y Mimiapan. Finalmente, 4136.70 hectáreas son adquiridas por Alonso de Villanueva Cervantes, a través de mercedes de tierras y compras. ${ }^{9}$

Alonso de Villanueva y Juana Altamirano, como otros fundadores de mayorazgos de la Nueva España, integraban al vínculo familiar un conjunto de bienes que ofrecían posibilidades excepcionales, en cuanto a las utilidades que podían generar, mediante el sistema de alquiler y aprovechamiento, tanto de fincas urbanas como rústicas, que años más tarde se incrementaron. Por ello fueron foco de interés para que quedaran en manos de su primogénito: Alonso de Villanueva Cervantes, y que se iría transmitiendo a sus hijos legítimos "prefiriendo el mayor al menor y el varón a la mujer". En caso de que Alonso de Villanueva muriera sin sucesión masculina, heredaría una mujer y en falta de todos ellos, debía suceder en el mayorazgo el segundogénito: Juan de Villanueva Cervantes. A falta de descendientes de este segundo heredero, los instituidores llamaban a Ana, luego a Isabel y finalmente a Catalina de Villanueva Cervantes, estableciéndose su sucesión bajo las mismas condiciones que para Alonso y Juan de Villanueva Cervantes.

También fijaron el orden sucesorio de los apellidos del linaje, buscando así que los descendientes de Alonso de Villanueva Cervantes

${ }^{9}$ Barrera Gutiérrez, "La propiedad de la familia", pp. 13-41. 
continuaran luciendo el apellido "Villanueva Cervantes" y los descendientes de Juan, Ana, Isabel y Catalina de Villanueva el apellido "Villanueva Altamirano". Así como el escudo de armas como una forma de mantener la memoria de la familia instituidora que luchaba por volver ilustre su apellido. Esta acción también la hallamos con Juan Gutiérrez Altamirano, quien señaló que el poseedor del mayorazgo estaba obligado a usar el apellido "Altamirano" y las armas de la familia. ${ }^{10}$

Las cláusulas y condiciones de los fundadores preveían quiénes y en qué orden serían los "llamados" a la sucesión en caso de fallecer sin descendencia el primero, para que con las futuras generaciones no se litigara el derecho de sucesión. Los litigios fueron una de las vicisitudes obligadas, a las que se enfrentaron casi todos los poseedores de mayorazgos. Las disputas por la titularidad en algunos casos fueron breves pero en otros se prolongaron, por lo que se transferían de una generación a otra.

Aun en casos en los que había descendencia directa y legítima del primogénito y que por ello eran evidentes los derechos del sucesor, éstos fueron cuestionados muchas veces. Se hacían reinterpretaciones de la ley o de los deseos del fundador. Esta caracterización corresponde al pleito que sostuvo Ana de Villanueva Cervantes, tercera poseedora del Mayorazgo de Villanueva, con Carlos de Luna y Arellano, su primo, en 1666, ${ }^{11}$ y Francisca de Villanueva Altamirano, cuarta titular del vínculo, con Carlos de Luna y Arellano en 1678. ${ }^{12}$ En muchos casos los demandantes no aspiraban realmente a modificar la sucesión, sino que era el pretexto para que los legítimos sucesores se vieran forzados a otorgarles algún beneficio económico, a cambio de finiquitar el litigio, ${ }^{13}$ como se recoge, por ejemplo, en el caso de Ignacio Manuel de Villanueva Altamirano con José Felipe

\footnotetext{
${ }^{10}$ AGN, Vínculos y mayorazgos, vol. 4, exp. 1, ff. 151-174.

${ }^{11}$ AGN, Vínculos y mayorazgos, vol. 193, exp. 9, ff. 1-6 y 44v-76.

12 Biblioteca Nacional de España (en adelante BNE), Sede de recolectores, PORCONES/26/12, f. 47.

${ }^{13}$ Artís Espriu, Familia, riqueza y poder, pp. 118-119.
} 
de Villanueva Altamirano, octavo poseedor del Mayorazgo de Villanueva, en $1791 .^{14}$

La nueva forma de herencia establecida por Alonso de Villanueva Cervantes y Juana Altamirano permitiría ser una estrategia efectiva para mantener la riqueza, bienes y prestigio a los titulares, pero también garantizar la tranquilidad financiera de la familia. Por ejemplo, una importante dote que garantizase el futuro de una hija en un convento. Ello implicaba varias cosas para la familia: confirmar el estatus, mantenerse en la cima de la escala social, buenas relaciones con los miembros del clero y relación en los círculos sociales y políticos de Toluca y México. Además, el que una hija profesara en algún convento fue una costumbre común de las principales familias novohispanas asentadas en la Ciudad de México.

Así, tanto Alonso de Villanueva y Juana Altamirano trataron con una serie de cláusulas y condiciones, hasta donde fuera posible la conservación y acrecentamiento de los bienes, así como el lustre a la familia, debido a que consideraban: "que los bienes que se parten y se dividen se suelen perder y consumir"; añadían: "y que quedando agregados e impartibles permanecen, se aumentan y los deudos, parientes de los que le poseen, pueden ser socorridos y las casa y estados se ennoblecen y así vienen los linajes a ilustrarse y hacer de ella memoria". ${ }^{15}$

\section{El acrecentamiento de los bienes rurales y su disposición a colonos españoles}

Durante los siglos xviI y xviI, muchos propietarios de haciendas ubicadas en el valle de Toluca, como los Suárez de Peralta o Altamirano seguían privilegiando las actividades que giraban en torno a la ganadería y al cultivo de cereales. En el caso de Alonso de Villanueva Cervantes, primer titular del vínculo familiar, continuó con esas actividades en la propiedad agraria heredada en usufructo a través de

${ }^{14}$ AGN, Vínculos y mayorazgos, vol. 196, exp. 3, f. 46v.

${ }^{15}$ AGA, Otzolotepec, Villa Cuauhtémoc, México, exp. 23/2255, f. 61. 
su fraccionamiento en tres partes. La primera extensión consolidó la hacienda denominada Magdalena o Mayorazgo, centro rector de las demás haciendas y ranchos, donde se construyeron edificios de administración, habitacionales para que en ella residiera el titular, una iglesia visitada por el cura de Otzolotepec y desde luego una tienda para las necesidades de los trabajadores.

La segunda dio forma a un rancho destinado para el resguardo del ganado, y finalmente, la tercera fortaleció la hacienda ganadera denominada, a veces, como la Vaquería o de Yeguas. Esta hacienda se conformaba por un sitio de estancia de ganado mayor, 1755.61 hectáreas, y se ubicaba en La Sabana Grande. Además, Alonso de Villanueva para contar con más extensiones para la ganadería, arrendó algunas tierras ubicadas en La Sabana Grande hacia 1641, entre ellas las tierras de la hacienda de Lope Serrano, conformada por nueve caballerías, 385.11 hectáreas, por un periodo de dos años. Por ese tiempo debía pagar 1100 pesos y 200 fanegas de cebada, 50 cargas de paja, 30 fanegas de maíz y seis puercos cebados de dos años. ${ }^{16}$

Alonso de Villanueva resulto ser tan activo y emprendedor como su padre a la hora de trabajar y ampliar los límites de las tierras, así, la extensión de la tierra sufrió serias transformaciones en su extensión durante el siglo xvir y hasta la primera mitad del xix. Esta práctica se realizó de acuerdo con la disponibilidad de tierras de los pueblos supuestamente desocupadas, huecos, que más tarde reconocerían como suyas, y de baldíos. Tan importante como las tierras fue el control del agua, un recurso abundante y esencial para asegurar las cosechas y mitigar la sed de los rebaños. Otro elemento que contribuyó al crecimiento de la propiedad fue las fuerzas políticas y económicas de la familia Villanueva Cervantes en el seno de la sociedad colonial. En esta nueva etapa de conformación, la ocupación del suelo no fue condicionada por su importancia productiva, así ocuparon tantas superficies planas y susceptibles de ser irrigadas, especialmente

\footnotetext{
${ }^{16}$ Archivo General de Notarías del Estado de México (en adelante AGNEM), Notaría núm. 1 de Toluca, cuad. 14, L1, ff. 87-88v.
} 
para la producción de trigo, espacios montañosos y poco fértiles, así como de bosques para el ganado.

El nuevo ciclo de conservación y ampliación de la tierra inició en 1605 y se cerró en 1643, con los programas de formalización de los derechos de propiedad, conocidos con el nombre de composiciones en aquella época. La política de composiciones de tierras fue implementada por Felipe II, a partir de dos cédulas suscritas en 1591. Si bien las motivaciones para llevar a cabo aquellas disposiciones fueron de acuerdo con las circunstancias y necesidades: la recaudación de dinero para incrementar los ingresos y fortalecer las finanzas de la Hacienda Real, así como para sustentar una Armada para cuidar y proteger sus intereses. Sobra decir que la medida dio lugar a que la Corona reclamara su potestad y derechos sobre los terrenos baldíos, en calidad de bienes realengos para ordenar todas las tierras, ${ }^{17}$ para corregir una situación que se producía al margen o en contra de la ley por parte de los colonos o por las propias autoridades virreinales en materia de tierras baldías o realengas a través de exigir títulos y documentos a quienes las habían ocupado.

La composición fue un acto jurídico mediante el cual una persona obtenía en reconocimiento legal de las ocupaciones irregulares mediante la aportación de una cantidad considerable de dinero a la Corona. En adición a lo anterior, cabe señalar que quienes han referido a las composiciones, como Francisco Solano, François Chevalier, Margarita Menegus, María Cristina Torales Pacheco y Sergio Carrera Quezada, refieren que este acto jurídico permitió la legalización de grandes propiedades agrarias que constituyeron parte sustancial de la tierra que dio origen a las haciendas y ranchos de colonos españoles, por un lado. Y por el otro, la Corona continuó su política proteccionista a los pueblos, una vez que quedaron fuera de toda composición, no obstante, algunos de ellos entran en el proceso voluntariamente para obtener títulos de tierras. Mariano Peset y Margarita Menegus señalan que aunque había normas que cobijaban

${ }^{17}$ Solano, Cedulario de tierras, documentos 131, 132 y 133. 
a los pueblos, componen sus posesiones en la medida del avance de la propiedad española. ${ }^{18}$

En el valle de Toluca el proyecto de las disposiciones referentes a las confirmaciones adquiere matiz durante el mandato del virrey García Sarmiento de Sotomayor, conde de Salvatierra. En 1643, el virrey nombró jueces para su ejecución y ajustó composiciones, entre otros, con Bartolomé Salazar, Magdalena Tabera, Alonso de Villanueva Cervantes, Felipe de Sámano y Miguel Vázquez de Peralta. Estos dueños de tierras recibieron despachos de composición por sus propiedades sin que las autoridades novohispanas conocieran su situación jurídica, pues lograron pactar de manera individual y no de manera colectiva con el virrey García Sarmiento la suspensión de las visitas de Nicolás Gutiérrez de Bazeval, juez de composiciones, en sus propiedades a cambio de un pago a las arcas reales.

Alonso de Villanueva Cervantes solicitó al virrey García Sarmiento la composición de sus tierras, el 3 de septiembre de 1643, que poseía en "términos" de los pueblos de Jilotzingo, Mimiapan, Otzolotepec y el valle de "Matalcingo". Villanueva Cervantes se comprometió, a cambio de los nuevos títulos, pagar una cuota a las arcas reales: 400 pesos. ${ }^{19}$ Dos días después de la solicitud, el virrey ordenaba a Nicolás Gutiérrez de Bazeval no realizar la medición de las tierras de Villanueva Cervantes, quien había entregado una relación de sus bienes para poner en orden su propiedad. Una vez cumplido con los requisitos, el virrey le admitió a Villanueva Cervantes la composición de: "una hacienda pequeña de ganado mayor y menor, y caballerías de tierra de labor de maíz y cebada”, el 17 de septiembre de $1643 .^{20}$

${ }^{18}$ Peset y Menegus, "Rey propietario", pp. 584-590. Durante el siglo XVI y XVII fueron reiteradas las disposiciones reales para proteger la propiedad de los pueblos, tales como la de 31 de mayo de 1535, 20 de noviembre de 1578, 8 de marzo de 1589 y 1 de noviembre de 1592 .

${ }^{19}$ AGA, Otzolotepec, Villa Cuauhtémoc, México, exp. 23/2250, leg. 1, ff. 49-58v.

${ }^{20}$ AGN, Mercedes, vol. 46, ff. 259-259v y AGA, Otzolotepec, Villa Cuauhtémoc, México, exp. 23/2255, leg. 1, ff. 42-47v. 
Por las características de la composición es difícil saber con precisión la cantidad de tierra compuesta, probablemente fue toda la propiedad vinculada, es decir, 9876.72 hectáreas, así como espacios de los pueblos que fueron acaparados y tierras baldías que simplemente habían sido ocupadas sin títulos desde 1605, que corresponden a 475.68 hectáreas de tierras. Villanueva Cervantes, a través de este medio, validó legalmente una extensión de tierras de 10352.4 hectáreas, que se mantuvo por 200 años, persistencia atribuible, en parte, a los hábiles mecanismos de control, a pesar del descontento social, los reclamos y la activa y organizada lucha agraria por parte de los pueblos. A principios del siglo xviII los pueblos se vieron obligados a arrendar algunas tierras del mayorazgo.

De forma similar procedió Felipe de Sámano Turcios, quien el 3 de septiembre de 1643 solicitó al virrey la composición de sus propiedades que se encontraban en "términos" de los pueblos de Otzolotepec, Huitzizilapan y Xochicuautla. Al igual que en el caso de Villanueva Cervantes, García Sarmiento ordenó a Gutiérrez de Bazeval que eximiera del proceso examinador las tierras de Sámano Turcios, pues contaba con títulos legítimos y se había comprometido a pagar la cantidad de 300 pesos. Sámano Turcios compuso: "una hacienda de labor de maíz y cebada y ganado", así como "caballerías de tierras y sitios de estancia de ganado mayor y menor". ${ }^{21}$ Además, en "términos" de los pueblos de Xochicuautla y Atarasquillo, Miguel Vázquez de Peralta solicitó y compuso: "una hacienda de ganado mayor y menor y tierra de labor de maíz y cebada". Vázquez de Peralta ofreció pagar la cantidad de 300 pesos a la caja real. ${ }^{22}$

En aproximadamente cuarenta años, Alonso de Villanueva había incrementado la superficie rural, hecho que sin duda enmarcó cuatro pequeños lunares que eran los pueblos de Otzolotepec, Jilotzingo, Mimiapan y Xonacatlán. Hacia 1667, las 10352.4 hectáreas se distribuían de la siguiente manera: un sitio de estancia para ganado menor

${ }^{21}$ AGN, Mercedes, vol. 46, ff. 259v-260r

${ }^{22}$ AGN, Mercedes, vol. 46, ff. 345r-345v. 
denominado Zacualpa, uno llamado Tepetzingo, otro conocido como Ostotitlán, uno más llamado Tlameloguan y uno ubicado "hacia la banda del pueblo de Jilotzingo, así como tres sitios en unos montes, es decir, 6242.16 hectáreas; dos sitios de estancia para ganado mayor en La Cerca General, 3511.22 hectáreas; dos caballerías de tierras entre la cerca de Jiquipilco y Mimiapan, siete caballerías fuera de La Cerca General, y otras cinco caballerías de tierras en diferentes lugares, 599.06 hectáreas.

En su conjunto estas propiedades estuvieron en manos de Alonso, Leonor y Ana de Villanueva Cervantes, primero, segundo y tercer poseedor del Mayorazgo, así como en posesión de Francisca, Juan José, José Ventura, Agustín, José Felipe e Ignacio de Villanueva Altamirano, cuarto, quinto, sexto, séptimo, octavo, noveno y décimo titular. La rica porción territorial fue poco deseable para Ana de Villanueva, ya que no siguió con el sistema de explotación que se había delineado durante el siglo xvi y la primera mitad del siglo xvir, y dispuso de nuevas prácticas económicas a través de contratos agrarios que se llevaban a cabo por periodos usualmente de dos, cuatro o seis años. Esta situación se repitió con igual claridad en los siguientes siete poseedores, que descendían de la línea de Juan de Villanueva Cervantes y Juana Muñoz de Morales.

De esta manera, en la atractiva zona territorial comprendida entre los pueblos de Otzolotepec, Jilotzingo, Xonacatlán y Mimiapan llegaron personajes de distintas partes del valle de Toluca para aprovechar lo favorable del clima, las grandes extensiones de tierras fértiles ubicadas en la planicie y las susceptibles de ser irrigadas por una amplia red de canales desprendida de los ríos para la producción de cereales, así como los espacios montañosos y poco fértiles, pero con fuentes de agua y propicios para pastar importantes hatos de borregos, reses, mulas y caballos. Además, para aprovechar la mano de obra de los trabajadores indígenas para el cultivo y corte de trigo y maíz. A través de esta práctica la familia obtenía ingresos seguros sin tener que invertir tiempo y trabajo para obtener cuotas de capital. Sin embargo, las ganancias no se derivaron en inversiones hacia el comercio, la minería o diversos negocios. Situación que más tarde afectó a algunos titulares. 
A principios del siglo xviII, el mayorazgo estaba consolidado, aunque no era tan grande en extensión territorial en comparación con el que poseía Pedro Rincón de Ortega, establecido dentro de la jurisdicción de la villa de Aguascalientes, o el de Fernando de la Campa y Coss, ubicado en Zacatecas. Pero contaba con importantes haciendas. En 1785, Agustín de Villanueva Altamirano, séptimo titular, señalaba que la calidad de las tierras era excepcional, de ahí que en la hacienda Magdalena se podían sembrar: 61 fanegas de maíz, 45 de haba, 52 cargas de trigo y 72 de cebada. En la hacienda Concepción y sus ranchos: 58 fanegas de maíz, 57 de haba, 77 cargas de trigo y 35 de cebada, y en la hacienda de San Pedro se sembraban: 92 fanegas de maíz, 65 de haba, 15 cargas de trigo y 20 de cebada. Finalmente, en la de Santa Rosalía y anexos: 46 fanegas de maíz, 36 de haba, 28 cargas de trigo y 18 de cebada.

En total se podían obtener 20560 fanegas de maíz, 2030 de haba, 2600 cargas de trigo y 2175 de cebada. Por la venta de lo producido se recaudaría la cantidad de aproximadamente 41452 pesos anuales. Referente a la ganadería, otro de los pilares importantes, se podían tener 1000 becerros que producirían 500 arrobas de queso, y 500 borregos de los cuales se podían obtener 300 arrobas de lana. Según los cálculos de Villanueva Altamirano los gastos anuales ascenderían a 20790 pesos, dejando como utilidad 20661 pesos, cantidad decorosa para que la familia viviera dignamente. ${ }^{23} \mathrm{El}$ volumen de las estimaciones de las cosechas nos indica que el maíz representaba uno de los principales productos del campo y para el comercio, seguido del trigo, la cebada y el haba.

José Felipe de Villanueva Altamirano, a diferencia de Agustín de Villanueva, su padre, y de otros poseedores del vínculo, fue el único que

${ }^{23}$ Agustín de Villanueva señaló que la calidad de las tierras era excepcional, pues calculaba que con una fanega de maíz sembrada se cosechaban 80 fanegas, de una fanega de haba se producía 10 fanegas, de una carga de trigo se producían 15 más, y de una carga de cebada 15 cargas. El precio de la fanega de maíz y de haba en almoneda era de un peso, una carga de trigo a seis pesos y una carga de cebada a 12 reales. AGN, Vínculos y mayorazgos, vol. 197, exp. 8, ff. 4v-5v. 
arriesgo en las actividades del campo produciendo maíz, trigo y haba, e hizo trabajar a los indios de Otzolotepec, Xonacatlán, Mimiapan y Jilotzingo, como lo hicieron muchos de sus arrendatarios, quien los empleaba durante el tiempo de la siembra y la cosecha. Entre 1799 y 1802 cultivó en la hacienda Magdalena: en 1799 un potrero que formaba parte de la hacienda Magdalena y entre 1801 y 1802 el rancho Osco.

No obstante, la mayoría de los bienes rurales así como los urbanos se encontraban en manos externas, quienes proporcionaban el soporte económico principal para la familia Villanueva. Naturalmente, las percepciones de cada uno de los bienes tanto del campo como de la ciudad fueron diferentes, habiendo años en que los ingresos fueron mayores en comparación con otros. Por ejemplo, en 1794, José María de Castro, por el arrendamiento de la hacienda San Agustín, pagó 350 pesos y 800 en 1798 y 1802. En 1794, Mario González, por el arrendamiento del rancho Dado pagó 55 pesos, cuatro años después Marcelina Antonia Favila entregó 85, y para 1802, Teodoro Gutiérrez pagó 140 pesos. La diferencia de los ingresos también lo podemos observar en las fincas urbanas. En 1793, la casa ubicada en la calle de la Canoa se rentaba por 825 pesos. Para 1797, fructificaba 1 100, y en 1801, la casa se rentaba por 500 pesos. Resulta bastante claro que existieron cambios económicos anuales de los arrendamientos de todas las propiedades del Mayorazgo de Villanueva, base de los poseedores del vínculo y sus familias, que generaron satisfacer las necesidades con decoro de la familia, pero también cuando los recursos no fueron suficientes generaron una crisis económica.

\section{La crisis económica y la desintegración de la fortuna familiar}

Un factor que desestabilizo a la familia Villanueva durante la cuarta década de siglo xvin fue el económico, aunque no representa un caso aislado. En situación semejante se encontraron diversos poseedores de mayorazgos, comerciantes, hacendados y funcionarios públicos. Según Gisela von Wobeser, debido a que se padecía una escasez endémica de circulante, a que los productores contaban con reducido 
capital propio y porque el reino estuvo sujeto a sucesivas crisis económicas. ${ }^{24}$

En tanto Horst Pietschmann señala que la falta de circulante y de medios de pago se recrudeció a finales del siglo xviII, a causa de las reformas borbónicas que estuvieron orientadas a reforzar la centralización del poder del rey, eliminando todo aquello que se opusiera a tal fin. Pero también estaban dirigidas a la extracción de una mayor contribución para las arcas de la Corona a través de los "préstamos forzosos" y la "consolidación de vales reales". ${ }^{25}$ Ante las dificultades económicas, un amplio número de personas recurrieron a las instituciones crediticias más importantes de la Nueva España: la Iglesia y los conventos, debido a que manejaban un amplio capital, producto de las dotes que pagaban las novicias al ingresar en ellos, de las cuantiosas donaciones que recibían, de las ganancias que obtenían de sus inversiones y de las obras pías que administraban. ${ }^{26}$

Estas instituciones incursionaron en el aspecto financiero, que consistía en el préstamo de dinero mediante censo consignativo o depósito irregular. El depósito irregular fue el mecanismo más utilizado para hacer inversiones de capital mediante préstamos durante el siglo XviII. A través de éste se prestaba cierta cantidad a determinada persona o institución, prestatario o deudor, cobrando réditos anuales por dicho préstamo y, al término del plazo establecido en el contrato, de recuperar el principal. ${ }^{27}$

Una de las diferencias entre el censo consignativo y el depósito irregular es que el primero implicaba una obligación real y no personal, es decir, la obligación estaba fincada sobre el bien y no sobre la persona. Además, las obligaciones del censo desaparecían si el bien

\footnotetext{
${ }^{24}$ Von Wobeser, "Los créditos de las instituciones", p. 176 y El crédito eclesiástico, pp. 7-10.

${ }_{25}$ Pietschmann, Las reformas borbónicas.

${ }^{26}$ Von Wobeser, El crédito eclesiástico, pp. 51-67 y "Los créditos de las instituciones", pp. 178-179.

${ }^{27}$ Von Wobeser, San Carlos Borromeo, pp. 92-93, y El crédito eclesiástico, pp. 39-48, y Pilar Martínez López-Cano, El crédito a largo plazo, pp. 21-50 y Pilar Martínez López-Cano y Valle Pavón, "Los estudios sobre el crédito colonial", p. 28.
} 
sobre el cual estaba impuesto se perdía o se deterioraba. Mientras que en el caso del depósito irregular, establecía un compromiso personal, la deuda no desaparecía si los bienes que respaldaban el censo se deterioraban y se ampliaban las opciones de garantía a fiadores u otros bienes muebles. ${ }^{28}$ Cuando no existían condiciones que aseguraran la seguridad de las inversiones se negaban los préstamos.

A pesar de que los bienes, sujetos a vínculo, eran inalienables e indivisibles, muchos poseedores, haciendo uso de la disposición real de 1695, obtuvieron permisos especiales para gravar diversos bienes para mejorar la condición de ciertos bienes. La disposición real de 1695 tenía un claro objetivo: salvaguardar el bienestar, el lustre y asegurar la continuidad de las buenas familias de la Nueva España, es decir, flexibilizar las leyes para su permanencia. Hacia 1798 y 1799 la Corona facilitó la enajenación de bienes vinculados siempre y cuando su propósito fuera socorrer al soberano y a su real hacienda. ${ }^{29}$ Eran frecuentes los casos en los que se necesitaba el dinero para construir o reparar algún inmueble, como es el caso de María Josefa Guerrero Dávila Fernández quien obtuvo, en 1748, del convento de San Bernardo 40000 pesos, por nueve años, para reedificar las casas de su mayorazgo. ${ }^{30}$ El conde de Santiago de Calimaya, en 1777, solicitó a la Audiencia su autorización para gravar los bienes vinculados en 130000 pesos para arreglar sus casas. ${ }^{31}$ En otros casos, el destino que se le daba al dinero obtenido era para pagar deudas o para redimir censos o depósitos irregulares, como se recoge, por ejemplo, en el caso de Manuel Rodríguez Balda, quien en 1779 obtuvo del convento de Regina Coeli 21000 pesos por tres años, para redimir gravámenes que tenía a favor del mismo convento. ${ }^{32}$

En el caso de los Villanueva Altamirano, la inestabilidad económica los obligó a solicitar al convento de San Agustín, en la tercera

\footnotetext{
${ }^{28}$ Von Wobeser, "Los créditos de las instituciones", p. 181.

${ }^{29}$ Menegus, El cacicazgo en Nueva España, p. 56.

${ }^{30}$ Von Wobeser, El crédito eclesiástico, pp. 57-58.

${ }^{31}$ González Polo, El palacio de los condes, p. 24.

${ }^{32}$ Von Wobeser, El crédito eclesiástico, p. 57.
} 
década del siglo xviII, y la Encarnación, entre 1740 y 1790, varios préstamos mediante depósito irregular. Los préstamos tuvieron una importancia en la vida económica de la familia para seguir con el prestigio, la ostentación y la opulencia, entre otros, no obstante, marcó la vida y administración de seis titulares como consecuencia de la disminución de la fortuna. En la tercera década del siglo xvir, José Ventura de Villanueva, quinto titular, solicitó al convento de San Agustín la cantidad de 6000 pesos a censo redimible, respaldando el crédito con las casas ubicadas en el Puente de Palacio. ${ }^{33}$ Este préstamo se liquidó a finales de la misma década.

En 1741, Juan José de Villanueva, sexto titular, solicitó un préstamo por la cantidad de 100000 pesos al convento de la Encarnación para reedificar algunas casas y tiendas. La concesión del crédito implicó el censo de varias fincas urbanas ubicadas en el centro de la Ciudad de México, además al pago anual de réditos de cinco por ciento, es decir, 5000 pesos. Otro indicador de las dificultades financieras que atormentaban a la familia lo constituye el préstamo solicitado por José Ventura de Villanueva, séptimo titular, en 1749. En ese año obtuvo la cantidad de 2000 pesos, utilizados para pagar el entierro de su esposa Francisca Barrientos. Al año siguiente solicitó 600 pesos, para gastos por el fallecimiento de una hija, y el préstamo de 1000 pesos, concedido en 1752, dinero que usó para gastos de profesión de una hija en el convento de la Concepción. ${ }^{34}$ La solicitud de créditos entre 1740 y 1752 al convento de la Encarnación refleja que las utilidades de los bienes, tanto urbanos como rurales, no eran suficientes para satisfacer las necesidades de la familia con decoro.

Después de 27 años, en 1781, el nuevo poseedor Agustín de Villanueva, ante la falta de capital propio, solicitó un préstamo por la cantidad de 8000 pesos de las arcas del convento de la Encarnación. ${ }^{35}$ Por esa cantidad Villanueva se comprometía a pagar anualmente 1000 pesos de principal, más 400 pesos de réditos. También todo el

\footnotetext{
33 AGN, Tierras, vol. 2792, exp. 15, ff. 455r-460v.

${ }^{34}$ AGN, Vínculos y mayorazgos, vol. 197, exp. 7, f. 123v.

${ }^{35}$ AGN, Vínculos y mayorazgos, vol. 196, exp. 3, ff. 1v-3v y 7-11v.
} 
sobrante de dinero percibido al final del año. Esta medida fue planteada con el objetivo de que en el menor tiempo posible se pagara el préstamo de los 8000 pesos. Además, ante cualquier contratiempo que sufriera el poseedor, el inmediato sucesor debía reconocer las deudas contraídas por sus antecesores. Mediante esta cláusula el convento aseguraba el reconocimiento y el pago de los préstamos. En muchos casos se trataba de involucrar al inmediato sucesor, a pesar de que sus intereses como heredero podían quedar afectados, como una forma de garantizar los préstamos. Esto se debió al hecho de que los bienes urbanos y rurales, generalmente tenían impuestos diversos gravámenes a favor de diferentes acreedores y no constituían una garantía adecuada. Sin embargo, la exigencia de garantías dependía del monto del préstamo, la reputación del prestatario, el plazo por el que se concedía el préstamo y la seguridad que ofrecían los bienes que se iban a hipotecar. El préstamo contraído no solo parece que hubiera servido para atajar la raíz del problema, sino que, por el contrario, engrosaba periódicamente la deuda.

En 1785, ante la falta de capital se vio obligado a solicitar otro préstamo por la cantidad de 10000 pesos. ${ }^{36}$ Para garantizarlo, el convento de la Encarnación impuso las siguientes condiciones: por la cantidad de los 10000 pesos debía pagar de réditos 5\% anual, es decir 500 pesos, todo el sobrante anual, que el inmediato sucesor -José Felipe de Villanueva Altamirano- reconociera el préstamo solicitado, así como los anteriores. Los bienes que quedaron hipotecados fueron la casa ubicada en la calle de la Canoa y las haciendas Magdalena, Concepción, San Pedro y Santa Rosalía, así como los ranchos Santos, Tejocote y sus agregados, Osco y Santa Gertrudis. ${ }^{37}$

La cantidad solicitada, una parte, fue destinada para cubrir una dote de 4000 pesos, y 2000 pesos para gastos de una de sus hijas en el convento de la Encarnación. La otra parte del dinero se utilizó para cubrir los gastos de casamiento de su hijo José Felipe con Ana María

${ }^{36}$ AGN, Vínculos y mayorazgos, vol. 196, exp. 3, ff. 12-27 y vol. 197, exp. 4, ff. 2-3v. ${ }^{37}$ AGN, Vínculos y mayorazgos, vol. 196, exp. 3, f. 14. 
de Saldívar. ${ }^{38}$ El préstamo, como muchos otros, fue solicitado por la falta de capital y de bienes que sirvieran para dar una dote conventual o matrimonial, para sufragar gastos de matrimonio o familiares. Esto refleja que los poseedores solamente contaban con los bienes del mayorazgo y no tenían otros bienes que en determinado momento pudieran ser útiles. Por ello, dependieron en forma generalizada del crédito, lo que agravó aún más la situación financiera.

Además, en 1785, Agustín de Villanueva, con el fin de obtener más recursos, trato de vender la hacienda denominada San Agustín, que formaba parte del mayorazgo familiar. Villanueva, para no solicitar la autorización de la Audiencia y vender rápidamente la propiedad trató de integrarla al proceso de composiciones. Así, a través de una módica cantidad pretendía obtener el reconocimiento legal de una finca. No obstante, a pesar de presentar testigos no logró la composición, ${ }^{39}$ debido a que no comprobó claramente que la hacienda no formaba parte del vínculo, además la hacienda era la base de sustento de una capellanía desde 1615 .

La falta de capital también perjudicó las finanzas de José Felipe de Villanueva Altamirano, noveno poseedor. Al carecer de recursos económicos se vio obligado a solicitar dinero a algunos arrendatarios. En 1788, solicitó a Ignacio Gallarza la cantidad de 1000 pesos. ${ }^{40} \mathrm{Al}$ año siguiente le pidió por adelantado el pago de los arrendamientos de un potrero y el rancho San Antonio. ${ }^{41}$ Gallarza entregó a José Felipe la cantidad de 2550 pesos. De esta cantidad 1800 pesos correspondían al pago de tres años, de 1789 a 1791, de renta por el rancho San Antonio y 750 correspondían a cinco años, de 1789 a 1793, de renta por el potrero. ${ }^{42}$

A pesar de los préstamos contraídos la situación financiera de José Felipe de Villanueva no mejoró. En 1791, con el objetivo de mejorar

\footnotetext{
${ }^{38}$ AGN, Vínculos y mayorazgos, vol. 197, exp. 4, ff. 4-6.

${ }^{39}$ AGN, Tierras, vol. 3570, exp. 2, f. 14.

${ }^{40}$ AGN, Vínculos y mayorazgos, vol. 190, exp. 8, ff. 3-6.

${ }^{41}$ AGN, Mimiapan, Xonacatlán, México, exp. 23/2430, leg. 1, f. 148.

42 AGN, Vínculos y mayorazgos, vol. 193, exp, 1, f, 28.
} 
las condiciones de tres viviendas que se encontraban en la "esquina que mira al palacio virreinal y a las dos plazas principales", en la Ciudad de México, solicitó al convento de la Encarnación 81000 pesos. En este caso para lograr el préstamo hipotecó una casa que se ubicaba en el puente de Olatero y una de la calle de la Canoa. ${ }^{43}$ Desde luego la adquisición de capital aseguraba, momentáneamente, el saneamiento de las deudas, pero por otra parte, se adquiría un compromiso que podía ser por un gran periodo. Durante la segunda mitad del siglo xviII, los diferentes titulares del mayorazgo, acostumbrados a vivir de sus rentas, resultaron incapaces para crear riqueza o hacer inversiones productivas, es decir, el dinero no generó más dinero, de ahí que procedieran a solicitar préstamos con el objetivo de mejorar la situación de algunos bienes urbanos, para asegurar el pago de deudas y gastos familiares. Sin embargo, por los constantes préstamos solicitados, seis poseedores quedaron sujetos a la institución crediticia, por lo que el "verdadero" beneficiario económico del Mayorazgo de Villanueva fue el convento de la Encarnación.

Lo verdaderamente importante fue que la precariedad financiera a la que se enfrentó Juan José, José Ventura, Agustín, José Felipe, Ignacio y María Francisca de Villanueva Altamirano, no puso en riesgo alguna propiedad vinculada, de ahí su trascendencia. Pedro Ignacio de Echevers, cuarto marqués de San Miguel de Aguayo, agobiado por los conflictos familiares y las deudas, a finales del siglo XVIII y principios del XIX, cedió algunos bienes a los acreedores pues su deuda, en 1806 excedía el medio millón de pesos. ${ }^{44}$ Ante la situación financiera en que se encontraba el Mayorazgo de Villanueva, a finales del siglo xviII, la Audiencia intervino con el propósito de sanear las finanzas y evitar la desintegración de los bienes vinculados. Para ello, propuso la designación de un juez conservador. ${ }^{45}$ Esta figura también fue impuesta al Mayorazgo de Santiago de Calimaya. Carlos

\footnotetext{
43 AGA, Jilotzingo, Villa Cuauhtémoc, México, exp. 23/2255, leg. 1, ff. 87-88.

${ }^{44}$ AGN, Vínculos y mayorazgos, vol. 196, exp. 3, f. 63.

${ }^{45}$ González Polo, El palacio de los condes, p. 24.
} 
III dispuso que la Audiencia nombrara al conde un juez conservador para que se hiciera cargo de sus "débitos, gravámenes y atrasos". ${ }^{46}$

En el caso de los Villanueva la designación del juez conservador corrió a cargo del virrey, en 1792. Dicho nombramiento lo extendió a favor de Ciriaco González Carbajal, oidor de Audiencia. ${ }^{47}$ Bajo la nueva forma de administración la situación financiera mejoro notablemente a través de los años. Esta cuestión se ve reflejada en el ingreso anual que se percibía de los bienes arrendados y en la pensión anual del poseedor. Por ejemplo, en 1793 la renta de los bienes urbanos y rústicos generó la cantidad de 12638 pesos y para 1803 fue de 19861 . Mientras que la cantidad anual percibida por el titular en 1793 fue de 2400 pesos, para 1803 ascendió a 4000 pesos, ${ }^{48}$ cantidades similares a la de un curato promedio. De 1792 a 1839 se refleja un periodo estable sobre los arrendamientos anuales y la estabilidad financiera, factores determinantes para que el mayorazgo se mantuviera y persistiera hasta 1839.

En ese año, Francisca de Villanueva, último poseedor, y José María Sevilla, su esposo, solicitaron ante el juez de primera instancia de la Ciudad de México Manuel Zosaya Bermúdez, la desvinculación del Mayorazgo de Villanueva en virtud del decreto de 7 de agosto de $1823{ }^{49}$ Esta medida reformista había sido planteada en 1820 en España y fue acogida por el Congreso Constituyente, es decir, el Congreso dio vigencia retroactiva a una norma peninsular. ${ }^{50}$

Las fincas rústicas fueron valuadas, por Lorenzo Carrera y José María González, en aproximadamente 165413 pesos y dos reales, y cuya superficie se calculó en no menos de 8130.1 hectáreas. Mientras que las fincas urbanas fueron valuadas, por José del Mazo y Joaquín de Heredia en 243609 pesos. El conjunto de los bienes vinculados

\footnotetext{
${ }^{46}$ AGN, Vínculos y mayorazgos, vol. 196, exp. 3, ff. 64-65 y 67.

${ }^{47}$ AGN, Vínculos y mayorazgos, vol. 196, exp. 3, ff. 64-65 y 67.

${ }^{48}$ AGN, Vínculos y mayorazgos, vol. 190, exp. 7, ff. 55-60 y vol. 191, exp. 1, ff. s/f.

${ }^{49}$ AGA, Otzolotepec, Villa Cuauhtémoc, México, exp. 23/2255, f. 71.

${ }^{50}$ Dublán y Lozano, Legislación mexicana, pp. 662-664 y AGN, Indios, vol. 224, exp. 83, s/f.
} 
ascendía a unos 409022 pesos y dos reales. ${ }^{51}$ De acuerdo con la ley de desvinculaciones a cada uno le correspondía la misma cantidad. Practicadas las diligencias sobre la desvinculación, a principios de mayo de 1839 el juez de primera instancia Manuel Zosaya Bermúdez declaró legalmente la división de un patrimonio que había dado fama, fortuna y que había formado parte de una tradición familiar, pues había sido transmitido de generación en generación durante aproximadamente doscientos treinta y cuatro años. Así es como se desintegró un mayorazgo que formó parte de una familia novohispana y decimonónica.

\section{Consideraciones finales}

El florecimiento de la gran propiedad de la familia Villanueva, en los pueblos de Otzolotepec, Mimiapan, Jilotzingo y Xonacatlán estuvo determinado, generalmente, por la gran fertilidad de la tierra, la abundancia de agua y la mano de obra. Aunado a estos factores naturales se encontraba en una estratégica zona entre el valle de Toluca y el valle de México, exactamente en la ribera oriental del río Chignahuapan. Características que en gran medida favorecieron el interés de los Villanueva por establecerse y poseer esas ricas tierras, así como integrarlas en el mayorazgo familiar.

El conjunto de bienes que conformaron el "Mayorazgo de Villanueva" permitieron a cada titular gozar de prestigio, de relaciones de amistad y de matrimonio con familias respetadas, preservar el buen apellido y las armas del linaje, y como punto fundamental disfrutar de una enorme riqueza. Pero también asumían el compromiso de conservar los bienes y en la medida de lo posible incrementarlos para a su vez transferirlos en herencia a una nueva generación. Estas acciones y otras más permitieron que los bienes se mantuvieran durante aproximadamente dos siglos y medio.

Durante ese tiempo el conjunto de bienes estuvo en manos de once personajes. Además, las propiedades se conservaron en buen estado,

${ }^{51}$ AGA, Otzolotepec, Villa Cuauhtémoc, México, exp. 23/2255, ff. 87r-87v. 
aunque no rindieron los mismos frutos, ante ello se frenó la prosperidad, el desarrollo de los bienes y la economía de la familia. Para contrarrestar esta situación se solicitaron una serie de préstamos que comprometieron los bienes, principalmente los urbanos. Si a esto le sumamos el despilfarro, el ocio y la irresponsabilidad de algunos de los titulares de no generar riqueza a partir de las ganancias obtenidas, era inevitable que al correr el tiempo las crisis económicas fueran más recurrentes. Lo verdaderamente importante fue que la precariedad financiera a la que se enfrentaron Juan José, José Ventura, Agustín, José Felipe, Ignacio y María Francisca de Villanueva Altamirano, no puso en riesgo alguna propiedad vinculada, de ahí su trascendencia.

Asimismo, la importancia del mayorazgo como una institución para proteger los bienes a través del tiempo, pero también salvaguardar la riqueza, el lustre y asegurar la continuidad de las buenas familias. Finalmente, es importante mencionar que detrás del título ostentoso de "mayorazgo" se hallaban varias realidades más complejas: problemas de sucesión, administración, rentabilidad, litigios por la posesión o propiedad de la tierra, entre otros. Problemáticas, que estuvieron presentes en el "Mayorazgo de Villanueva". 


\section{Fuentes}

\section{Siglas}

$\begin{array}{ll}\text { AGN } & \text { Archivo General de la Nación } \\ \text { AGA } & \text { Archivo General Agrario } \\ \text { AGNEM } & \text { Archivo General de Notarías del Estado de México, Notaría } \\ & \text { núm. } 1 \text { de Toluca } \\ \text { BNE } & \text { Biblioteca Nacional de España }\end{array}$

\section{Bibliografía}

Artís Espriu, Gloria, Familia, riqueza y poder. Un estudio genealógico de la oligarquía novohispana, México, CIEsas, 1994.

Barrera Gutiérrez, Florencio, "La propiedad territorial de la familia Villanueva en la ribera oriental del río Chignahuapan, siglo xvi", en Letras Históricas, núm. 9 (2013-2014), pp. 13-41.

Bermúdez, Gilberto, El Mayorazgo de la Higuera, Veracruz, Universidad Veracruzana, 1987.

Clavero, Bartolomé, Mayorazgo. Propiedad feudal en Castilla 1369-1836, Madrid, Siglo xxi de España Editores, 1989.

Chevalier, François, La formación de los latifundios en México, México, FCE, 1976.

Dublán, Manuel y José María Lozano, Legislación mexicana, México, Edición oficial, imprenta del Comercio, 1986.

Fernández de Recas, Guillermo, Mayorazgos de la Nueva España, México, Biblioteca Nacional de México, 1965.

Gómez Serrano, Jesús, Un mayorazgo sin fundación. La familia Rincón 
Gallardo y su latifundio de Ciénega de Mata, 1593-1740, México, Instituto Cultural de Aguascalientes-Consejo de la Crónica de AguascalientesUniversidad Autónoma de Aguascalientes, 2006.

González Polo, Ignacio, El palacio de los condes de Santiago de Calimaya, México, Colección del Distrito Federal, 1987.

González y Serrano, Comentario histórico, crítico y jurídico a las leyes de Toro, tomo II, Madrid, Imprenta y Fundación de M. Tello, 1876.

Ladd, Doris M., La nobleza mexicana en la época de la independencia, 17801826, México, FCE, 1984.

Margadants, Guillermo, "El mayorazgo novohispano, producto natural de un Zeitgeist, y anatema para el siguiente", en Anuario Mexicano de Historia del Derecho, vol. 11 (1999-2000), pp. 225-258.

Martínez López-Cano, María del Pilar, "Las capellanías en la ciudad de México en el siglo xvi y la inversión de sus bienes dotales", en María del Pilar Martínez López-Cano, Gisela von Wobeser y Juan Guillermo Muñoz, Cofradias, capellanías y obras pias en la América colonial, México, unam, 1998, pp.191-209.

Martínez López-Cano, María del Pilar, y Guillermina del Valle Pavón, "Los estudios sobre el crédito colonial: problemas, avances y perspectivas", en María del Pilar Martínez López-Cano y Guillermina del Valle Pavón, El crédito en Nueva España, México, Instituto Mora-El Colegio de Michoacán-El Colegio de México-IIH-unam, 1998, pp.13-32.

Menegus, Margarita, "El cacicazgo en Nueva España", en Margarita Menegus y Rodolfo Aguirre Salvador, El cacicazgo en Nueva España y Filipinas, México, cesu-unam, 2005, pp. 13-70.

Peña, José Francisco de la, Oligarquía y propiedad en la Nueva España (1550-1624), México, FCE, 1983. 
Peset, Mariano y Margarita Menegus, "Rey propietario o rey soberano", en Historia Mexicana, vol. 43 (1994), pp. 563-599.

Pietschmann, Horst, Las reformas borbónicas y el sistema de intendencias en Nueva España, México, FCE, 1994.

Romero Alaniz, Fermín, "Los dueños y la producción agropecuaria de la hacienda de San Nicolás Peralta. De la colonia a los primeros años del México independiente", en Claudio Barrera Gutiérrez, Transformación y desarrollo del municipio de Lerma. Una historia con trascendencia, México, Amecrom, 2011, pp. 15-52.

Solano, Francisco, Cedulario de tierras. Compilación de legislación agraria colonial (1497-1820), México, unam, 1984.

Vargas-Lobsinger, María, Formación y decadencia de una fortuna. Los mayorazgos de San Miguel de Aguayo y San Pedro del Álamo, 1583-1823, México, inh-unam, 1992.

Villaseñor y Villaseñor, Alejandro, Los condes de Santiago. Monografia histórica y genealógica, México, Tipografia de "El Tiempo", 1901.

Wobeser, Gisela von, San Carlos Borromeo. Endeudamiento de una hacienda colonial (1608-1729), México, unam, 1980.

, El crédito eclesiástico en la Nueva España, siglo xvIII, México, UNAM, 1994.

, "Los créditos de las instituciones eclesiásticas de la ciudad de México en el siglo xvin", en María del Pilar Martínez LópezCano y Guillermina del Valle Pavón, El crédito en Nueva España, México, Instituto Mora-El Colegio de Michoacán-El Colegio de México-IIH-unam, 1998, pp. 176-202. 